\title{
PERANCANGAN MEDIA INFORMASI TRADISI TUMBILOTOHE DI GORONTALO MELALUI NARRATIVE PHOTOSTORY BOOK
}

\author{
Syarifah Fatimah Setiasih Niode ${ }^{1}$, Baso Indra Wijaya Azis ${ }^{2}$ \\ Desain Komunikasi Visual Fakultas Seni dan Desain Universitas Negeri Makassar \\ ${ }^{1}$ syarifafsniode@gmail.com \\ ²basoindrawijayaazis@gmail.com
}

\begin{abstract}
ABSTRAK
Perancangan ini bertujuan menciptakan media informasi komunikasi visual yang dapat mengkomunikasikan nilai-nilai yang terkandung dalam makna Tumbilotohe untuk remaja Gorontalo. Kumpulan data dalam perancangan diperoleh melalui observasi, studi pustaka, wawancara/survey pada remaja Gorontalo, dan wawancara kepada Dewan adat Provinsi Gorontalo. Konsep desain dalam perancangan narrative photostory book Tumbilotohe adalah konsep desain harmonis yang bertujuan untuk dapat dengan lebih kuat dan jelas diterimanya materi pesan yang dikomunikasikan kepada target audiens. Hasil perancangan ini adalah narrative photostory book Tumbilotohe yang berjudul "TUMBILOTOHE Cahaya Diatas Cahaya". Perancangan ini berfungsi sebagai media informasi komunikasi visual tentang tradisi budaya Tumbilotohe terhadap remaja di Gorontalo.
\end{abstract}

Kata Kunci: Tumbilotohe; Photo Story; Narrative Photostory Book; Fotografi

\begin{abstract}
This design aim to create a visual communication information to communicate values and means of Tumbilotohe for Gorontalo young generations. The collection of data in the design was obtained through observation, literature, interview/survey with the Gorontalo young generations, and interview with the Dewan adat Provinsi Gorontalo. the design concept in this narrative photostory book of Tumbilotohe is harmonize that invented to create a strong and clearly massage to communicate to the audience target. This design produced a narrative photostory book of Tumbilotohe named "TUMBILOTOHE Cahaya Diatas Cahaya". This design is created to become a visual communication informations about Tumbilotohe tradition culture for Gorontalo yuong generation.
\end{abstract}

Keywords: Tumbilotohe; Photo Story; Narrative Photostory Book; Photography

\section{PENDAHULUAN}

Di Indonesia sendiri sebagai negara kepulauan yang terbentang dari Sabang sampai Merauke memiliki keberagaman suku dan budaya tradisi sebagai ciri khas daerah masingmasing. Keanekaragaman budaya tradisi tersebut menjadi kebanggaan bagi masyarakat Indonesia. Seiring kemajuan peradaban manusia saat ini, ancaman globalisasi terhadap eksistensi jati diri bangsa di bidang budaya tersebut tercermin dari semakin terkikisnya budaya lokal. Budaya lokal atau budaya tradisi seolah-olah tergantikan oleh budaya luar, khususnya budaya barat disegala aspek kehidupan masyarakat Indonesia. Generasi muda saat ini semakin kurang tertarik terhadap hal-hal yang berbau tradisi. Segala sesuatu yang berkaitan dengan budaya tradisi dianggap kuno, ketinggalan zaman dan hanya milik generasi sebelumnya saja. Pada hakikatnya, budaya tradisi sebagai produk asli para leluhur terkandung banyak nilai-nilai luhur pembentuk jati diri bangsa. Contoh nilai luhur yang terdapat dalam tradisi budaya Tumbilotohe, dalam tradisi budaya ini terdapat makna dan pesan terkait nilai-nilai suci keagamaan. Ekspresi seni berbaur menyatu dengan ekspresi terhadap yang kudus. 
Tumbilotohe, Kata ini berasal dari bahasa Gorontalo, awalnya terdiri dari kosa kata tumbilo, artinya pasang (nyalakan) dan tohe artinya lampu. Memasang lampu yang ditunjuk dalam pengertian kata tersebut berhubungan dengan budaya lokal untuk memaknai perstiwa terkait peribadatan dalam agama islam yaitu turunya lailatul qadar pada malam ke 27, 28 dan 29 Ramadhan setiap tahunya. Asal usul kebudayaan ini menurut berbagai sumber (Niode, 2007) berawal dari tradisi yang diwariskan orang-orang terdahulu saat Islam menjadi agama kerajaan di Gorontalo sekitar abad ke-16. Dalam Al-qur'an surah Al-Qadr ayat 97 , disebutkan bahwa pada malam-malam itu Allah SWT akan menurunkan berkah-Nya dengan menyetarakan waktu beribadah menjadi setara dengan seribu bulan pada setiap anugerah itu datang. Semarak malam anugerah tersebut menjadi waktu yang sangat didambakan untuk beribadah sebanyakbanyaknya. Tak hanya itu, mereka juga akan saling bersilaturrahim mengunjungi keluarga dan tetangga bersuka ria untuk mengaji Qur'an bersama atau juga mengantarkan sedekah, zakat kepada yang dianggap pantas menerimanya menurut aturan agama.

Tetapi sudah menjadi hukum alam pada setiap akhir bulan berdasarkan penanggalan tahun Hijriah, bulan di langit menjadi gelap, sehingga umat islam yang akan sholat tarawih di masjid pada waktu seperti itu harus megunakan alat bantu penerangan jalan, mulai dari rumah hingga ke masjid. Awalnya mereka menggunakan getah kayu yang disebut damahu. Beriring waktu, makin berkurang maka dibuatlah lampu dengan bahan bakar minyak kelapa, lalu diganti dengan minyak tanah. Pada tahun 1990an selain minyak tanah dipasang pula lampu-lampu hias dengan menggunakan daya listrik. Demikianlah hingga kini, malam- malam yang penuh berkah dan suka cita yang di beri nama malam pemasangan lampu (huyi lo tumbilotohe) menjadi bagian dari kebudayaan Gorontalo. Aneka lampu penerang dan lampu hias dalam suasana bulan yang gelap dilangit menjadi panorama budaya yang menarik dan indah.

Selain nilai keindahan, Tumbilotohe juga menyampaikan pesan terkait nilai nilai suci keagamaan. Ekspresi seni berbaur menyatu dengan ekspresi terhadap yang kudus. Kebudayaan ini memiliki nilai strategi untuk dilestari-kembangkan. Pesan terkait nilai tersebut memiliki arti penting bagi Gorontalo tak hanya dari sisi semaraknya keindahan lampu, tetapi pula kedalaman makna substansinya yang turut menganggit nilai-nilai solidaritas (dalam hal pilihan waktu untuk mengeluarkan sedekah dan zakat), komunikasi dan silaturrahim untuk merawat kohesi-kohesi sosial.

Saat ini generasi muda di Gorontalo, masih menunjukkan antusiasme dalam perayaan tradisi Tumbilotohe setiap tahun. Namun hal ini hanya sekedar menjadi perayaan simbolis saja. Karena kurangnya pemahaman makna dan nilai-nilai yang terkandung dalam budaya Tumbilotohe. Masalah yang dihadapi ini dapat berdampak terhadap proses pelaksanaan tradisi dan proses pelestarian budaya Tumbilotohe itu sendiri.

Tujuan dari penelitian ini adalah merancang dan membuat media informasi komunikasi visual yang dapat mengkomunikasikan nilai-nilai yang terkandung dalam makna Tumbilotohe untuk remaja di Gorontalo sehingga dapat digunakan sebagai media pelestarian budaya Tumbilotohe di Gorontalo yang efektif dan komunikatif.

\section{METODE PENELITIAN}

Dalam perancangan ini, metode yang digunakan adalah Metode Penelitian Deskriptif. Metode penelitian ini terpusatkan pada pokok permasalahan yang ada serta menggambarkan fakta yang ada tentang suatu permasalahan yang sedang di selidiki.

Kajian kepustakaan yang dilakukan pada tahap ini yaitu mencari berbagai referensi berdasarkan kata kunci perancangan yang akan dibuat:
a) Tumbilotohe
b) Pengertian Budaya
c) Budaya Lokal
d) Tradisi

Kota Gorontalo antara lain di Jembatan Talumolo, Lapangan rektorat Universitas Negeri Gorontalo, Desa Tenggela, Desa 
Luwo'o, Jl. Andalas, Jl. Dua Susun, Kabila (Kab. Bone Bolango), Jl. Taman Surya, Jl. Taman Hiburan, dan Talaga.

Kuisioner Pada teknik pengumpulan data ini, dibuatkan daftar pertanyaan (questionnaire) berbasis digital yang diedarkan secara online ke masyarakat Gorontalo pada tanggal 11 November 2018. Dari hasil penelitian singkat tersebut dapat diperoleh kesimpulan respon dari masyarakat Gorontalo dapat dikelompokkan dalam kategori usia 14 19 tahun, usia 20 - 21 tahun, usia 23 - 50 tahun. Dari ketiga kelompok ini mengaku Tumbilotohe menarik, mengaku suka dengan budaya Tumbilotohe, dan mengaku bahwa budaya Tumbilotohe perlu dilestarikan. Namun pada usia rata-rata $14-19$ tahun hanya mampu menjawab pertanyaan essay (mengenai apa saja yang diketahui dari budaya tumbilotohe) dengan waktu pelaksanaan Tumbilotohe saja.

Dalam perancangan ini, metode analisis data yang digunakan adalah Deskriptif Photography Story kualitatif, Deskriptif artinya perancangan ini Narrative Photo story memfokuskan pada masalah dan fakta yang ada. Teknik/Jenis Fotografi saat ini. Menurut Moleong dalam Arifin, Teori Warna Fotografi (2010:26), penelitian kualitatif adalah penelitian layout yang bermaksud untuk memahami fenomena Prinsiprinsip Layout Strategi Informasi dan Komunikasi.

Wawancara Pada tahap ini didapatkan data dengan cara melakukan proses tanya jawab secara langsung/online dengan pihak yang bersangkutan seperti salah seorang budayawan Gorontalo, Alim S. Niode, serta beberapa masyarakat Kota Gorontalo yang tinggal atau menetap di asrama mahasiswa Gorontalao yang terletak di Jl. Sungai Cerekang, kota Makassar untuk mendapatkan data yang akurat mengenai persepsi masyarakat remaja Gorontalo tentang Tumbilotohe.

Observasi dan dokumentasi Dilakukan observasi langsung pada pelaksaan tumbilotohe pada Ramadhan 1437 H (2016) Ramadhan 1438 (2017), di beberapa titik tentang apa yang dialami oleh subyek penelitian, misalnya, perilaku, persepsi, pandangan, motivasi, tindakan sehari-hari, secara holistik dengan metode deskripsi dalam bentuk kata-kata dan bahasa (naratif) pada suatu konteks khusus yang alamiah dan memanfaatkan berbagai medode alamiah. (Sutikno, 2015).

Adapun hasil analisis yang didapatkan yaitu; Analisa Materi Komunikasi. Materi tentang tradisi budaya Tumbilotohe di Gorontalo, kemudian upaya pelestarian tradisi Tumbilotohe dengan mengkomunikasikan nilai dan makna yang terkandung didalam tradisi budaya ini. Sejarah tradisi budaya Tumbilotohe, berisi rangkuman mengenai asalusul Tumbilotohe di Gorontalo. Tumbilotohe, berisi tentang makna dan nilai tradisi Tumbilotohe, mengapa orang gorontalo melaksanakan Tumbilotohe dan bagaimana tradisi ini dilaksanakan di Gorontalo. Timeline, berisi tentang detil-detil rangkuman keseluruhan dari tradisi budaya Tumbilotohe.

Analisa target audiens menggunakan analisis STP. Dari hasil analisis STP, target audiens yang diperoleh ialah remaja atau generasi muda atau peserta didik di Gorontalo laki-laki dan perempuan usia 14-19 yang belum sempat mengenal atau mengetahui nilai dan makna budaya Tumbilotohe secara tutur atau lisan baik disekolah maupun dirumah, dimana remaja yang dimaksud adalah mereka yang lebih menyukai penyampaian informasi yang lebih ilustratif. Remaja yang lebih gemar membaca buku yang terdapat unsur visual, serta termasuk juga remaja yang mudah antusias, dan mereka mencari keragaman, kegembiraan, serta menikmati hal-hal yang baru dan penuh resiko.

Analisa Strategi Komunikasi. Tujuan Komunikasi Tujuan komunikasi dari penelitian ini antara lain untuk merancang media informasi dan komunikasi yang dapat membantu pelestarian makna dan nilai-nilai tradisi budaya Tumbilotohe di Gorontalo.

Strategi Visual Untuk strategi visual sendiri berpatokan pada target audiens maka dari itu, perancangan media informasi dan komunikasi yang nantinya akan dibuat menggunakan unsur-unsur komposisi, ilustrasi fotografi, 
layout, tipografi serta warna yang disukai oleh remaja.

Perencanaan Media Adapun usulan media yang akan digunakan yaitu Buku Photography Story. Buku Photography Story mampu menyampaikan pesan yang kuat, membangkitkan semangat, menghibur, dan dapat menggugah emosi pembaca menurut Abdul Rozack dalam (Ahmady, 2018). Perencanaan Buku Photography Story yang akan dibuat adalah berupa photo story narasi yang bertutur dari satu kondisi ke kondisi lainnya. Di dalam Buku Photography Story ini nantinya akan memuat informasi- informasi yang dapat mengkomunikasikan tentang makna dan nilai- nilai budaya Tumbilotohe dengan menggunakan ilustrasi foto atau fotografi secara runtun namun masih tetap ada keterangan penjelas disampingnya. Melalui ilustrasi foto, diharapkan target audiens atau remaja dapat lebih tertarik mengetahui budaya mereka sendiri dengan membaca buku dan dapat menerima informasi tentang makna dan nilai budaya Tumbilotohe dengan jelas.

\section{HASIL DAN PEMBAHASAN Konsep Desain}

Konsep desain yang diusung dalam perancangan buku adalah harmonis (Kamus Besar Bahasa Indonesia: Keselarasan), dimana dalam perancangan ini harmonis yang dimaksudkan adalah kerjasama antara elemenelemen materi pesan dan media yang digunakan mengarah kepada tujuan pencapaian informasi yang mudah diterima dan dipahami oleh target audiens. Konsep desain harmonis juga ditujukan untuk menarik perhatian target audiens, mulai dari penyampaian informasi tentang budaya tumbilotohe dengan gaya yang berbeda, penerapan materi visual seperti warna layout dengan menggunakan warna-warna netral untuk lebih menonjolkan elemen foto narasi dan menambah kesan kuat serta rapi, disamping itu penggunaan typeface yang tegas dan jelas dengan komposisi anatomi huruf yang tidak berbelit-belit memberi kesan simple dan ringan.

\section{Sumber Inspirasi}

Sesuai konsep desain, sumber inspirasi terkait dengan harmonis. Harmonis mewakili atau mempresentasikan prosesi tradisi budaya Tumbilotohe yang dilaksanakan di Gorontalo. Keselarasan antara subtansi maknanya maupun tampilan secara visual tumbilotohe yang menampilkan keindahan cahaya-cahaya yang semarak, dan disambut dengan penuh suka cita oleh masyarakat Gorontalo. Maka penyajian media informasi Narrative Photostory Book Tumbilotohe, akan menggunakan foto dengan beragam teknik pengambilan gambar yang dapat dengan mudah mengangkat atau mengilustrasikan (ke dalam foto) ruang sosial dari subjek/objek yang di foto yaitu budaya Tumbilotohe, sehingga pembaca dapat dengan mudah menerima dan kuat memahami isi/konten buku. Teknik visualisai yang digunakan, antara lain potrait, landscape, human interest, macro, photojournalism dan still life.

\section{Tipografi}

Mengacu pada konsep harmonis tipografi pada perancangan Photostory Book menggunakan 2 jenis font dari keluarga yang berbeda yaitu serif dan sans serif dengan pembagian font Garamond untuk headline dan font Sogoe UI untuk isi/bod copy.

\section{Warna}

Untuk warna rancangan buku (termasuk didalamnya background, layout, dan typeface) I dominasi oleh warna hitam, putih dan jingga sesuai dengan konsep harmonis dan gaya visual yaitu minimalis. Sedangkan untuk warna elemen konten (ilustrasi/foto) menggunkan warna komplementer dan warna analogus.

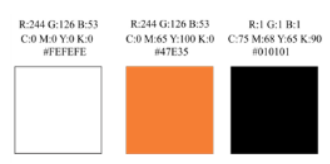

Gambar 1. Warna Layout Keseluruhan

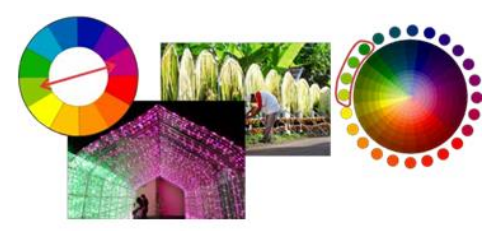

Gambar 2. Warna elemen foto 
Layout

Harmonis pada layout berarti penggunaan atau penyusunan elemen- elemen lebih kuat dalam menggambarkan atau menyampaikan informasi tetntang budaya tumbilotohe. Beberapa jenis layout yang digunakan antara lain rebus layout, mandarian layout dan jumble layout yaitu manajemen bentuk dalam bidang yang menampilkan perpaduan gambar dan teks disusun secara teratur sehingga membuat seuah cerita/narasi yang berpatokan pada bentuk-bentuk square/landscape/potrait.

Namun layout pada buku tetap mengusung gaya desain minimalis sehingga penggunaan jenis-jenis layout tersebut lebih mengarah kepada terfokuskannya target audiens/pembaca pada penyampaian informasi tentang budaya tumbilotohe.

\section{Proses Kreatif}

Proses kreatif berisi eksplorasi ide berupa sketsa cover, sketsa layout, sketsa isi dan juga berisi implementasi digital menggunakan yang menggunakan beberapa aplikasi antara lain, Adobe Photoshop untuk editing media pendukung dan media promosi, Adobe Lightroom CC untuk editing mood dan warna foto dan CorelDraw digunakan dalam mendesain, dan mengatur tata letak//layout.

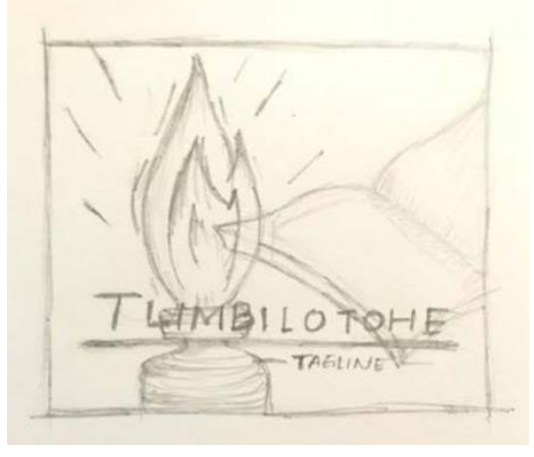

\section{Gambar 3 Sketsa cover Depan}

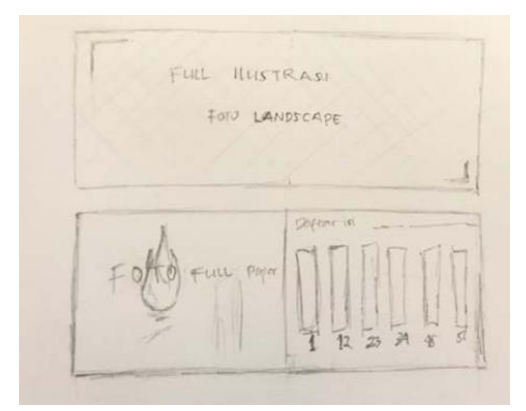

Gambar 4 Sketsa Layout isi buku: halaman pembuka dan daftar isi

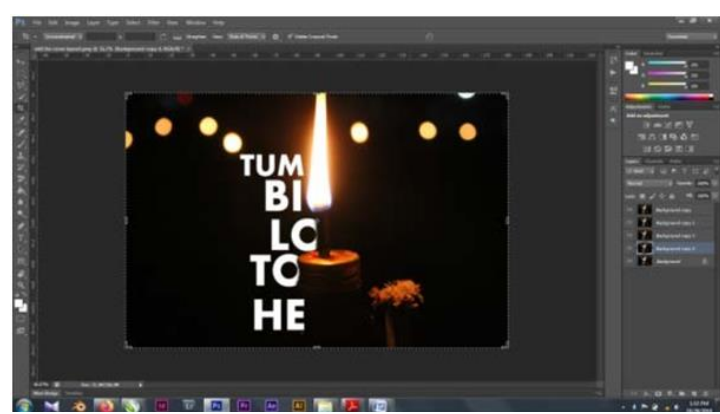

Gambar 5 Proses editing komposisi warna pada foto

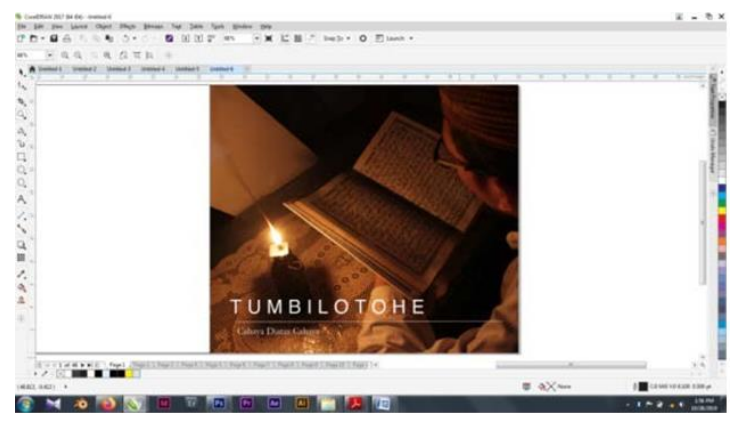

Gambar 6 Proses digitalisasi desain cover

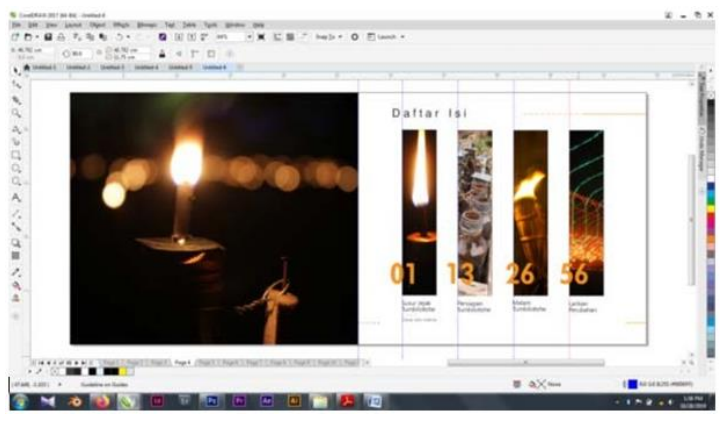

Gambar 7 Proses digitalisasi desain halaman awal

\section{Pembahasan \\ Deskripsi Media Perancangan Media Utama}

Menggunakan fotografi sebagai media informasi utamanya. Foto disajikan beruntun dengan esai atau narasi pendukung yang kemudian dikemas dalam Narrative Photostory Book yang berjudul "TUMBILOTOHE Cahaya Di atas Cahaya". Narrative Photostory Book ini berbentuk landscape dengan ukuran $27 \mathrm{~cm}$ x 23,5 cm dan total halaman 120 lembar. Layout didalam Narrative Photostory Book ini 
menggunakan layout campuran dengan finishing teknik digital printing dan jilid benang hardcover. Jenis kertas yang digunakan dibedakan menjadi dua macam, untuk bagian isi menggunakan kertas matte paper $150 \mathrm{gsm}$ sedangkan bagian cover menggunakan art paper $250 \mathrm{gsm}$.

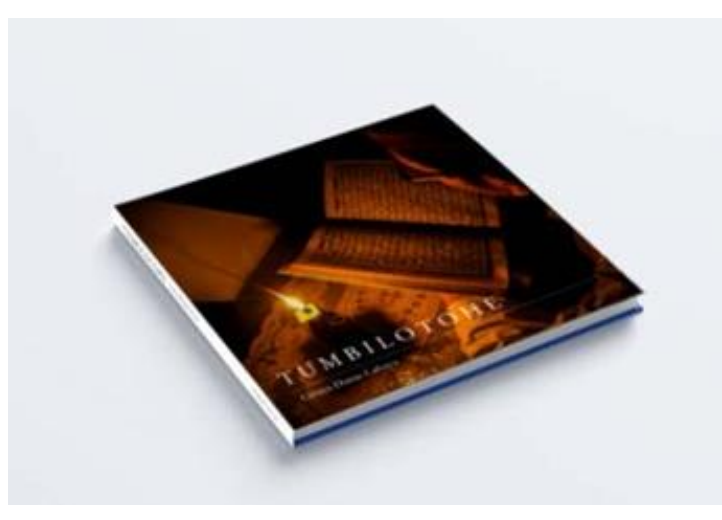

Gambar 8 Sampul Depan

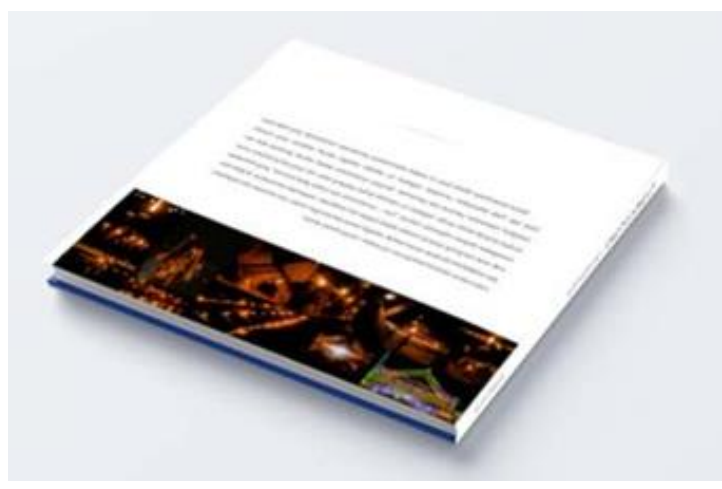

Gambar 9 Sampul Belakang

\section{Media Pendukung dan Promosi}

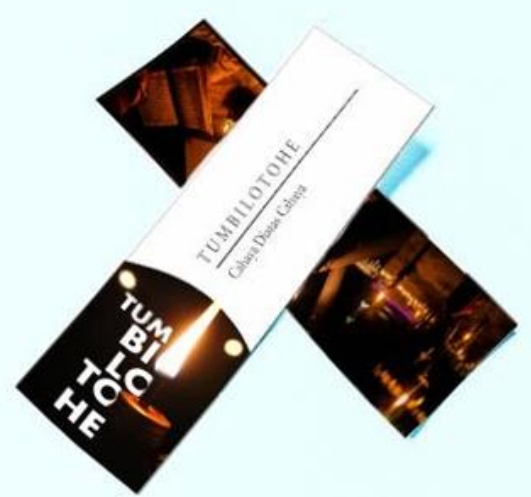

Gambar 10 Final Desain Pembatas Buku
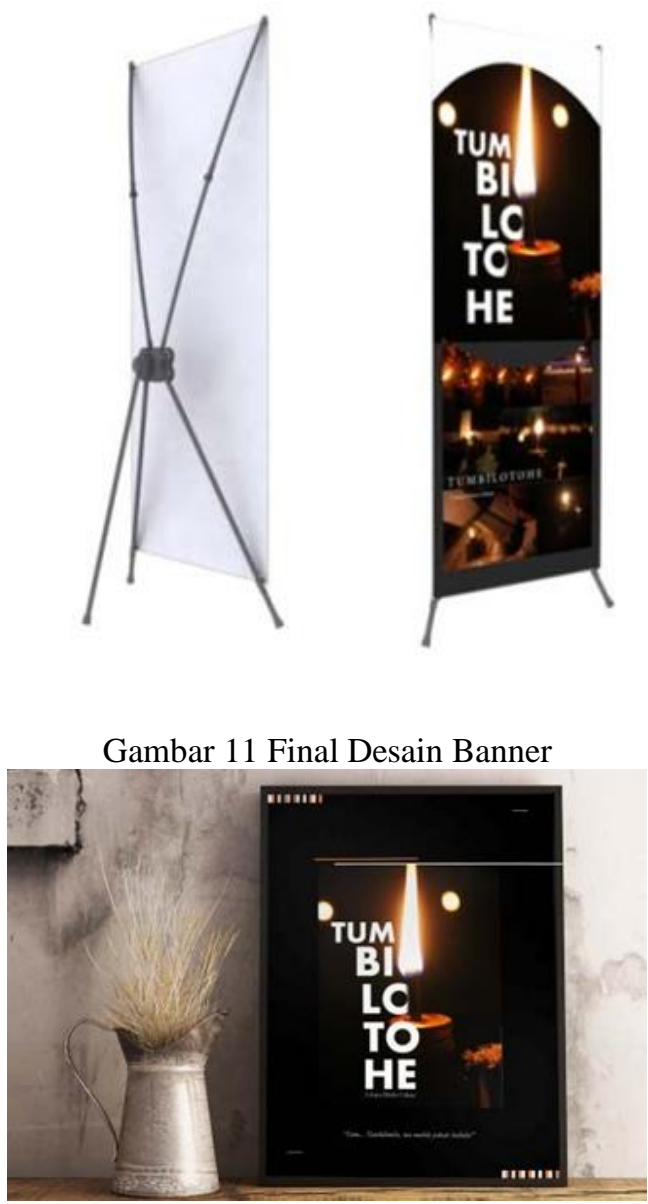

Gambar 12 Final Desain Poster A3

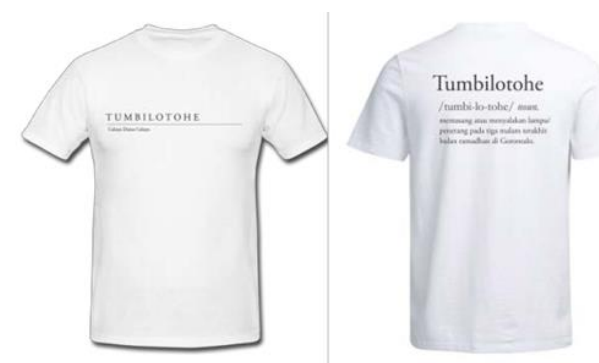

Gambar 13 Final desain T-shirt warna putih

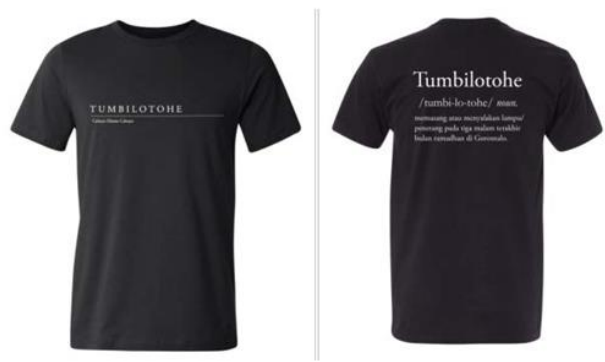

Gambar 14 Final desain T-shirt warna hitam 


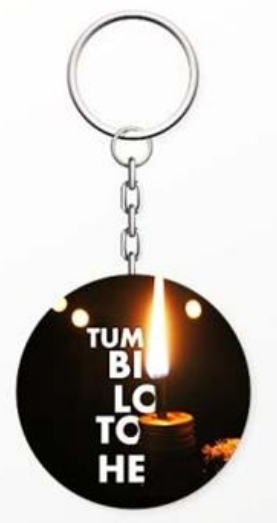

Gambar 15 Final desain gantungan kunci akrilik

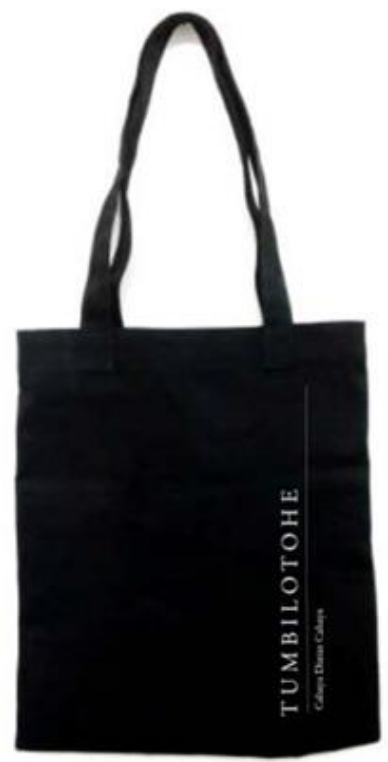

Gambar 16 Final desain tote bag
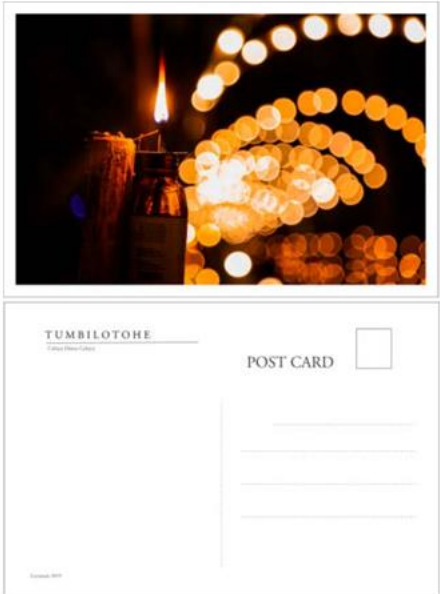

Gambar 17 Final desain post card depan dan belakang

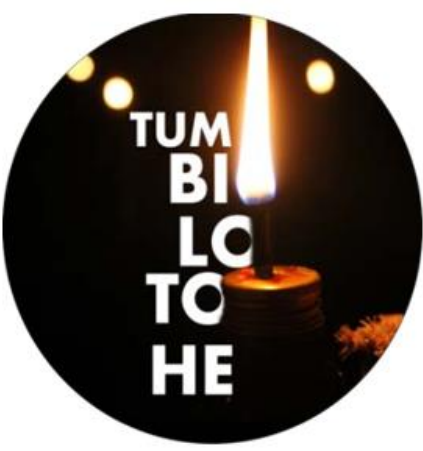

Gambar 18 Final desain sticker 2

\section{SIMPULAN DAN SARAN \\ Kesimpulan}

Berdasarkan dari pembahasan hasil perancangan narrative photostory book tumbilotohe, penulis dapat menarik kesimpulan yaitu:

1. Perancangan narrative photostory book tumbilotohe ini menjadi solusi untuk mengurangi minimnya pengetahuan dan pemahaman generasi muda di Gorontalo tentang nilai dan makna tradisi budaya tumbilotohe di Gorontalo dengan memberi wawasan melalui media yang lebih menarik agar tradisi budaya tumbilotohe dapat terlestarikan dengan baik.

2. Perancangan ini memiliki konsep desain harmonis yaitu kuat dan jelas serta menarik yang diperoleh dari hasil analisis target audiens yakni generasi muda di Gorontalo usia 14-19 tahun.

\section{Saran}

Dengan adanya narrative photostory book tumbilotohe ini diharapkan pelestarian tentang tradisi budaya daerah asli ini dikalangan masyarakat generasi muda Gorontalo dapat terjaga.

Adapun saran dalam membuat perancangan narrative photostory book tumbilotohe adalah materi fotografi yang perlu diperkaya dan memiliki kekuatan visual narasi yang lebih kuat agar tafsir target audiens tidak terlalu meluas dan fokus pada makna tradisi agar perancangan narrative photostory book ini kedepannya lebih baik dengan efisiensi manfaat perancangan lebih baik pula. 


\section{DAFTAR PUSTAKA}

Ahmady, A. A. (2018). PERANCANGAN BUKU STORY PHOTOGRAPHY PRODUKTIFITAS GARAM SEBAGAI MEDIA INFORMASI KEPADA MASYARAKAT.

ANGGARA, B. (2017). PERANCANGAN BUKU PHOTOGRAPHY STORY TARI REMO SEBAGAI UPAYA MELESTARIKAN KESENIAN TARI TRADISIONAL SURABAYA.

Arumsari, M. F. (2017). PERANCANGAN BUKU PHOTO STORY (DESIGNING OF PHOTO STORY BOOK). e-Proceeding of Art \& Design: Vol.4, No. 3.

Brilliananda, A. (2015). PERANCANGAN BUKU DOKUMENTASI BUDAYA LAIS MELALUI MEDIA FOTOGRAFI.

Karmadi, A. D. (2007). BUDAYA LOKAL SEBAGAI WARISAN BUDAYA. 1 .

Kindarto, A. (2007). Memotret dan Mengolah Foto Digital untuk Pemula. Jakarta: PT Elex Media Komputindo.

Melvina, E. (2015). EKSISTENSI KEBUDAYAAN PERTUNJUKAN PESTA SEKHUKHA PADA MASYARAKAT SUKU LAMPUNG DI KECAMATAN BALIK BUKIT KABUPATEN LAMPUNG BARAT. Fakultas Keguruan dan Ilmu Pendidikan Universitas Lampung.

Said, A. A. (2006). Dasar Desain Dwimatra. Makassar: Badan Penerbit UNM.

Surianto Rustan, S. (2008). Layout Dasar dan Penerapannya. Jakarta: Gramedia Pustaka Utama.

Sutikno, D. B. (2015). PENCIPTAAN BUKU ESAI FOTOGRAFI GREBEG BESAR YOGYAKARTA SEBAGAI UPAYA MEMPOPULERKAN FILOSOFI BUDAYA JAWA. Art Noubeau Vol.4 No. 2.

Tavip, A. C. (2018). Perancangan Buku Visual Adat Istiadat Suku Batak Toba Sebagai Bentuk Pelestarian Budaya. JURNAL SAINS DAN SENI ITS Vol. 7, No. 2.

Tinarbuko, S. (2015). DEKAVE Desain Komunikasi Visual - Penanda Zaman Masyarakat Globalisasi. Yogyakarta: Center ForAcademic Publishing Center.
WIjaya, T. (2016). Photo Story Handbook Panduan membuat foto cerita. Jakarta: Gramedia Pustaka Utama. 